\title{
Adherence to modern contraceptives among female refugee adolescents in northern Uganda: A prospective single cohort study
}

Ritah Bakesiima ( $\sim$ esmie.ritah@gmail.com )

Makerere University

Kristina Gemzell-Danielsson

Karolinska Institutet

Jolly Beyeza-Kashesya

Mulago Specialised Women and Neonatal Hospital

Elizabeth Ayebare

Makerere University

Amanda Cleeve

Karolinska Institutet

Elin C. Larsson

Karolinska Institutet

Rose Chalo Nabirye

Busitema University

\section{Research Article}

Keywords: Contraceptive adherence, contraceptive discontinuation, adolescents, refugees, teenage pregnancy

Posted Date: February 3rd, 2022

DOI: https://doi.org/10.21203/rs.3.rs-1314823/v1

License: (c) (1) This work is licensed under a Creative Commons Attribution 4.0 International License. Read Full License 


\section{Abstract}

Background: Contraceptive adherence is the current and consistent use of a contraceptive method as prescribed by a health worker or family planning provider so as to prevent pregnancy. Globally, adherence is lowest among adolescents. This has greatly contributed to the high burden of adolescent pregnancies. Adherence and reasons for discontinuation among refugee adolescents are poorly understood. The aim of this study was to determine the rates and predictors of adherence to modern contraceptives among female refugee adolescents in northern Uganda.

Methods: A prospective single cohort study, nested into a randomised controlled trial (RCT) assessing the effect of peer counselling on acceptance of modern contraceptives. The RCT was conducted among female refugee adolescents in Palabek refugee settlement, northern Uganda. The study involved 272 new starters of modern contraceptives who were followed up for six months from May 2019 to January 2020. The outcome was measured at one, three and six months after receiving a contraceptive method. Data was analysed using STATA version 14.0.

Results: Adherence rates were low and reduced over time. By the end of the six months, only $44 \%$ of the participants were using a contraceptive method. The commonest reasons for non-adherence were side effects and partner prohibition. Participants using long acting reversible contraceptives (LARC) were more likely to adhere compared to those who were using short acting reversible contraceptives (SARC) (OR: 3.37, 95\% Cl: 1.914-5.937, $p=<0.001)$. There was no difference in adherence between participants who received peer counselling and those who received routine counselling.

Conclusion: Adherence to modern contraceptives was low, leaving adolescents at risk of unintended pregnancies. Participants using LARC were more likely to adhere than those using SARC. Interventions addressing fear of side effects and partner prohibition should be studied and implemented to enable adherence to modern contraceptives.

\section{Introduction}

Adolescent pregnancy remains a global burden with an estimated birth rate of 44 births per 1,000 girls aged 15 to 19 years (1). In low-resource settings, approximately 770,000 girls under 15 years of age and about 12 million aged 15 to 19 years give birth annually (2), and an additional 3 million girls aged 15 to 19 years undergo unsafe abortions annually (3). In Uganda, adolescent births account for $14 \%$ of all births (4), majority of which are unintended (5). However, the rates are mentioned to be higher among the refugee adolescents than the nationals (6-8). This is so because of the insecurity and poverty they face, which leave them vulnerable to sexual exploitation, abuse, rape, transactional sex and early or forced marriages.

Adolescent pregnant women have a higher risk of pregnancy induced hypertension, systemic infections, puerperal endometritis and post-partum depression compared to those aged 20 to 24 years (9). Owing to 
the above mentioned complications, pregnancy and child birth contribute largest to mortality among adolescents world over $(10,11)$.

The high adolescent pregnancy rates are attributed to low contraceptive use, coupled with poor adherence to contraception (12). Use of modern contraceptives among female refugee adolescents in low resource settings is reported to be less than $10 \%(6,13)$. This low use is reported to be a result of fear of side effects, inadequate knowledge on contraceptives, partner prohibition and social acceptability $(6,14)$. The same reasons are believed to explain poor adherence to and discontinuation from contraceptives. Research among adolescents in Ghana showed a contraceptive adherence rate of $23 \%$ (15) while high discontinuation rates of $50 \%$ were reported among adolescents in Tanzania (16).

Several factors are reported to be associated with adherence to modern contraceptives among adolescents. These include age, education, and type of contraceptive used (17-20).

In order to curb the low adherence rates and high discontinuation rates, it is important to understand the contributing factors. However, neither the rates nor the predictors of low adherence and high discontinuation have been established among refugee adolescents. Therefore, this study aimed to determine the rates and predictors of adherence to reversible modern contraceptives among female refugee adolescents in northern Uganda.

\section{Methods}

\section{Study design:}

This was a prospective single cohort study, nested in a randomized controlled trial (RCT) which assessed the effect of peer counselling, compared to routine contraceptive counselling on acceptance of modern contraceptives among female refugee adolescents (21). This study was carried out in Palabek refugee settlement in northern Uganda, from May 2019 to January 2020. Participant recruitment occurred from May to July 2019, and participants were then followed for a period of six months till January 2020 . The reason for this short follow up period was because of the mobility of the refugees; they are always moving in and out of the settlement at will, either to go back to their native country or to look for employment opportunities outside the camp. Therefore, a longer follow up period would result in increased loss to follow up. The follow ups were done at one, three and six months after receiving a contraceptive method.

\section{Study setting:}

Palabek refugee settlement was established in April 2017 and is one of the newest refugee settlement in Uganda. It is situated at the border of Uganda and South Sudan. It hosts close to 55,000 refugees from South Sudan, $85 \%$ of whom are women and children (22). Palabek refugee settlement is burdened with adolescent pregnancy among girls aged 17 to 19 years with a prevalence of over $50 \%$ (6), and the 
settlement has four health centres which provide contraceptive services free of charge. The family planning services provided include contraceptive counselling, provision of condoms (both male and female), oral contraceptives, injectables, and insertion and removal of implants and intra-uterine devices (IUDs).

Study participants: A total of 272 female refugee adolescents aged 15 to 19 years who were new starters of reversible modern contraceptives participating in the RCT were consecutively enrolled into this study. The reversible modern contraceptives available were oral contraceptives (both combined and progestin only), the depo medroxyprogesterone acetate (DMPA) injectable, subcutaneous single rod contraceptive implants and copper IUD. Participants were excluded if they could not comprehend either English, Acholi or Arabic (the languages commonly used within the settlement), or were physically or mentally unable to consent or answer interview questions.

\section{Sample size estimation:}

The sample size formula for comparing means in two proportions by Hulley (23) was used. An error of 0.05 was assumed, with a power of $80 \%$. The proportion of adolescents who discontinued on a long acting reversible contraceptives (LARCs) was taken at 35\% (24) while the proportion of adolescents who discontinued on other contraceptives was taken at $60 \%$ assuming a $25 \%$ difference between the two groups. The proportion of refugee adolescents on LARCs was estimated to be $12.6 \%$ (13). After factoring these into the formula, we got a sample size of 272 participants. Assuming a $10 \%$ loss to follow up ( 0.1 $x 272)+272)$, the adjusted sample size would be 300 participants. Therefore, a total of 300 female refugee adolescents would be necessary to answer this objective.

Data collection: As part of the RCT (21), baseline information like social demographics, sexual and reproductive history, type of contraceptive received, and partner's characteristics was collected at the health centre where the participants received their contraceptives. This information was obtained with the help of an interviewer administered questionnaire. A contact locator was developed which had the participants' address, telephone numbers and contacts of their 'significant other' who could be a relative, spouse or friend. Participants were also given a small card with their particulars and an appointment date for their next follow up. Those who did not come to the health centre at the given appointment were traced with the help of the contact locator. In the event of a missed appointment, they were contacted by phone or home visited within two weeks of the missed appointment. A respondent was considered lost to follow up if she was not traced within the six months of the study. Information collected during follow up included continued use of the contraceptive method (adherence) or discontinuation, the reason for discontinuation, switching to other contraceptive methods, reasons for switching, and side effects experienced. Two trained research assistants conducted the interviews.

\section{Study variables:}


The outcome variable was "adherence to modern contraceptives" defined as the use of any contraceptive method in an ongoing and consistent manner as prescribed (25). For adherence to be achieved, both continuation and correct use of the contraceptives are required. Hence, a participant was termed as nonadherent if: i) the participant became pregnant during the previous month (and the pregnancy not attributed to method failure as judged by research assistants ii) missed her appointment and iii) missed taking three or more oral contraceptives during the month according to the Guttman scale (26). Selfreported non-adherence was used for all the other contraceptive methods. For the LARC methods, participants were regarded as adherent for the six-months follow up unless they reported removal of the method. Participants who self-reported pregnancy had to undergo an assessment to determine whether the pregnancy was due to method failure or non-adherence.

The predictor variables included socio-demographics like age, highest level of education attained, marital status, occupation, sexual and reproductive history like age at first sex, number of children alive, partner's characteristics and type of contraceptive given.

Statistical methods: Data were analysed using STATA version 14.0. Continuous variables were summarised as means and standard deviations if they were normally distributed, and as medians and ranges if skewed. Categorical variables were summarised as percentages and proportions. Adherence to contraceptives was analysed as a binary variable, with adherence coded as " 1 " and non-adherence as " 0 " at the different time points. Percent adherence at the different follow up times was then obtained. Predictors of adherence were assessed using Generalised Estimating Equations (GEE), with the exchangeable correlation matrix, family binomial and link logit. Bivariate analysis was done by fitting a model for each independent variable with the outcome. All the variables that gave a $p$-value $\leq 0.2$ at the bivariate analysis were considered for multivariate analysis. Also considered for multivariate were variables which are known to be of significance to adherence from previous research even though they had $p$-values greater than 0.2 .

At the multivariate analysis, GEE was run for all the variables which met criteria for it, and the nonsignificant ones ( $p>0.05)$ were dropped one at a time. Those which retained statistical significance were used to assess for interaction and confounding. Two-way product terms were formed between the variables and used in the assessment of interaction using the chunk test. A variable was considered a confounder if it caused a greater than or equal to $10 \%$ change in the odds ratio of adherence to contraceptive use. Odds ratios along with their $95 \%$ confidence intervals were reported, and statistical significance reported at $p<0.05$. Robust standard errors were used in the GEE analysis. To deal with those who were lost to follow up, both intention to treat (ITT) and per protocol analyses were conducted.

\section{Sensitivity analysis:}

This was conducted to assess if the participants who were lost to follow up had an impact on our study findings. We first grouped the lost to follow under non-adherent, and then re-analysed them under adherent, and conclusions were checked if they remained similar. 


\section{Ethical considerations:}

Ethical clearance was obtained from the School of Medicine Higher Degrees Research Ethics Committee (REC REF 2018-059), and from Uganda National Council of Science and Technology (SS 4876). We ensured that all participants gave their written informed consent before enrolling them into the study, and guaranteed their confidentiality with the use of number codes instead of participant names. For participants below 18 years, we did not seek for parental consent because it is stated in the National Policy Guidelines and Service Standards for Sexual and Reproductive Health and Rights, that all individuals seeking family planning services are eligible to receive the services regardless of their age, without need for verbal or written consent from parent, guardian or spouse, as long as they have received prior education or counselling about the contraceptives (27). All interviews were held in private places where discussions could not be over heard.

\section{Results}

\section{Participant flow}

A total of 279 participants were assessed for eligibility as new starters of modern contraceptives from the RCT. Amongst these, 7 were eliminated because they either did not meet the inclusion criteria (due to language barrier) or they declined to participate in the study. Therefore, 272 participants were enrolled in the study, of whom 113 were lost to follow up (figure 1).

\section{Baseline characteristics of study participants}

Most of the participants were older adolescents aged 18 to 19 years (86.6\%), had attained up to primary school as their highest level of education (73.5\%), and were cohabiting (46\%). Two thirds of the participants $(67.3 \%)$ had ever been pregnant, and $45.9 \%$ had more than one child. Regarding the partner's characteristics, most of the participants had partners within their age group (18 to 25 years). Most of the partners had attained up to secondary as their highest level of education (62.9\%), and were unemployed (41.9\%). At baseline, most of the participants were using the injectable contraceptive (45.6\%). See table 1.

Table 1

Baseline characteristics of the study participants $(n=272)$ 


\begin{tabular}{|c|c|c|}
\hline Variable & Number (n) & Percentage (\%) \\
\hline \multicolumn{3}{|l|}{ Age $($ median $=19$, range $=15$ to 19$)$} \\
\hline $15-17$ & 36 & 13.2 \\
\hline $18-19$ & 236 & 86.8 \\
\hline \multicolumn{3}{|l|}{ Highest level of education level } \\
\hline None & 17 & 6.3 \\
\hline Primary & 200 & 73.5 \\
\hline Secondary & 50 & 18.4 \\
\hline Vocational training & 5 & 1.8 \\
\hline \multicolumn{3}{|l|}{ Occupation } \\
\hline Self employed & 6 & 2.2 \\
\hline Employed & 5 & 1.8 \\
\hline Unemployed & 97 & 35.7 \\
\hline Peasant farmer & 105 & 38.6 \\
\hline Student & 59 & 21.7 \\
\hline \multicolumn{3}{|l|}{ Marital status } \\
\hline Single & 80 & 29.4 \\
\hline Cohabiting & 125 & 46.0 \\
\hline Married & 50 & 18.4 \\
\hline Divorced/separated & 17 & 6.3 \\
\hline \multicolumn{3}{|l|}{ Ever been pregnant } \\
\hline Yes & 183 & 67.3 \\
\hline No & 89 & 32.7 \\
\hline \multicolumn{3}{|l|}{ Number of children alive* } \\
\hline 0 & 8 & 4.4 \\
\hline 1 & 91 & 49.7 \\
\hline $2-4$ & 84 & 45.9 \\
\hline \multicolumn{3}{|l|}{ Partner's age } \\
\hline $18-25$ & 96 & 47.5 \\
\hline
\end{tabular}




\begin{tabular}{|c|c|c|}
\hline $26-35$ & 94 & 46.5 \\
\hline $36-60$ & 12 & 5.9 \\
\hline \multicolumn{3}{|l|}{ Partner's highest level of education } \\
\hline None & 5 & 2.5 \\
\hline Primary & 61 & 30.2 \\
\hline Secondary & 127 & 62.9 \\
\hline Tertiary & 9 & 4.5 \\
\hline \multicolumn{3}{|l|}{ Partner's occupation } \\
\hline Self employed & 20 & 9.9 \\
\hline Employed & 29 & 14.3 \\
\hline Unemployed & 85 & 41.9 \\
\hline Peasant farmer & 51 & 25.1 \\
\hline Student & 18 & 8.9 \\
\hline \multicolumn{3}{|l|}{ Type of counselling } \\
\hline Peer counselling (intervention) & 147 & 54.0 \\
\hline Routine counselling (control) & 125 & 46.0 \\
\hline \multicolumn{3}{|l|}{ Type of modern contraceptive } \\
\hline Condom & 19 & 7.0 \\
\hline Oral contraceptive (pill) & 42 & 15.4 \\
\hline Injectable contraceptive & 124 & 45.6 \\
\hline Implant & 85 & 31.3 \\
\hline Intra-uterine device (IUD) & 2 & 0.7 \\
\hline
\end{tabular}

\section{Adherence to reversible modern contraceptives among the study participants at the different follow up points}

A total of 253 participants (93\%) were found to have adhered to their contraceptives at one month, 178 (65.7\%) at three months, and $115(44.7 \%)$ at six months. Altogether, $17(6.3 \%)$ of the participants switched contraceptives due to side effects and ease of use, while $24(8.8 \%)$ discontinued use during the six months of follow up. The reasons for discontinuation were side effects $(57.1 \%)$, partner prohibition 
(23.8\%) and wish to have a child (19.1\%). A total of $113(44.0 \%)$ of the participants were lost to follow up. Thirteen of the participants were found pregnant at the end of the six months of follow up (table 2). Participants who switched contraceptives were treated as adherent in the bivariate and multivariate analyses.

\section{Table 2}

Adherence to contraceptives at each of the three follow up time points

\begin{tabular}{|lccc|}
\hline Adherence scale & One-month $\mathbf{n}(\%)$ & Three months $\mathbf{n ( \% )}$ & Six months (\%) \\
\hline Adhered & $253(93.0)$ & $178(65.7)$ & $115(44.7)$ \\
\hline Switched & $1(0.4)$ & $9(3.3)$ & $7(2.7)$ \\
\hline Discontinued & $1(0.4)$ & $14(5.2)$ & $9(3.5)$ \\
\hline Pregnant & $0(0.0)$ & $0(0.0)$ & $13(5.1)$ \\
\hline Lost to follow up & $17(6.2)$ & $70(25.8)$ & $113(44.0)$ \\
\hline
\end{tabular}

\section{Factors associated with adherence to modern contraceptives}

At bivariate analysis, the factors found to be significant $(p<0.2)$ were occupation, marital status, partner's education, partner's occupation, type of contraceptive used and time, as shown in table 3 . These variables were included in the multivariate analysis. In addition, age, education, ever been pregnant and number of children alive were also included in the multivariate analysis since they are known to be important for adherence from previous research. There was no difference in adherence between participants who received peer counselling and those who received routine counselling.

In the multivariate analysis, the variables which were found to be significant $(p<0.05)$ were type of contraceptive used and time, as shown in table 3 . These variables were assessed for interaction between each other and for confounding with other independent variables. However, there was neither interaction nor confounding. The results presented in table 3 are for Intention to treat (ITT) analysis.

\section{Table 3}

Factors associated with adherence to contraceptives (ITT) 


\begin{tabular}{|c|c|c|c|c|}
\hline Variable & $\begin{array}{l}\text { Crude OR } \\
(95 \% \mathrm{Cl})\end{array}$ & $\begin{array}{l}\mathrm{P} \text { - } \\
\text { value }\end{array}$ & $\begin{array}{l}\text { Adjusted OR } \\
(95 \% \mathrm{Cl})\end{array}$ & P-value \\
\hline Age (Mean=18.5, SD=0.8) & $\begin{array}{l}1.02(0.797 \text { to } \\
1.310)\end{array}$ & 0.864 & & \\
\hline $15-17$ & $\begin{array}{l}0.78(0.464 \text { to } \\
1.312)\end{array}$ & 0.350 & $\begin{array}{l}0.57(0.198 \text { to } \\
1.638)\end{array}$ & 0.296 \\
\hline $18-19$ & 1.00 & & & \\
\hline \multicolumn{5}{|l|}{ Education } \\
\hline None & $\begin{array}{l}0.77(0.374 \text { to } \\
1.598)\end{array}$ & 0.488 & $\begin{array}{l}1.49(0.344 \text { to } \\
6.455)\end{array}$ & 0.594 \\
\hline Primary & 1.00 & & 1.00 & \\
\hline Secondary & $\begin{array}{l}1.08(0.684 \text { to } \\
1.711)\end{array}$ & 0.737 & $\begin{array}{l}2.45(0.856 \text { to } \\
6.991)\end{array}$ & 0.095 \\
\hline Vocational training & $\begin{array}{l}0.84(0.196 \text { to } \\
3.628)\end{array}$ & 0.819 & $\begin{array}{l}1.83(0.357 \text { to } \\
9.370)\end{array}$ & 0.469 \\
\hline \multicolumn{5}{|l|}{ Occupation } \\
\hline Unemployed & 1.00 & & 1.00 & \\
\hline Employed & $\begin{array}{l}0.62(0.237 \text { to } \\
1.626)\end{array}$ & 0.332 & $\begin{array}{l}0.23(0.040 \text { to } \\
1.306)\end{array}$ & 0.097 \\
\hline Self employed & $\begin{array}{l}0.65(0.189 \text { to } \\
2.244)\end{array}$ & 0.496 & $\begin{array}{l}1.78(0.410 \text { to } \\
7.754)\end{array}$ & 0.441 \\
\hline Peasant farmer & $\begin{array}{l}1.21(0.791 \text { to } \\
1.846)\end{array}$ & 0.380 & $\begin{array}{l}1.05(0.515 \text { to } \\
2.156)\end{array}$ & 0.885 \\
\hline Student & $\begin{array}{l}0.72 \text { (0.438 to } \\
1.182)\end{array}$ & 0.194 & $\begin{array}{l}0.64(0.067 \text { to } \\
6.057)\end{array}$ & 0.695 \\
\hline \multicolumn{5}{|l|}{ Marital status } \\
\hline Married & 1.00 & & 1.00 & \\
\hline Cohabiting & $\begin{array}{l}0.94(0.562 \text { to } \\
1.562)\end{array}$ & 0.803 & $\begin{array}{l}0.96(0.470 \text { to } \\
1.953)\end{array}$ & 0.907 \\
\hline Divorced/Separated & $\begin{array}{l}0.54(0.245 \text { to } \\
1.183)\end{array}$ & 0.123 & $\begin{array}{l}0.55(0.187 \text { to } \\
1.597)\end{array}$ & 0.270 \\
\hline Single & $\begin{array}{l}0.66(0.380 \text { to } \\
1.137)\end{array}$ & 0.134 & $\begin{array}{l}0.98(0.371 \text { to } \\
1.993)\end{array}$ & 0.946 \\
\hline \multicolumn{5}{|l|}{ Ever been pregnant } \\
\hline Yes & 1.00 & & & \\
\hline
\end{tabular}



No
$0.80(0.548$ to
0.261

1.177)

Children alive

$\begin{array}{lll}0-1 & 1.00 \\ 2-4 & 0.99(0.631 \text { to } & 0.977 \\ & 1.563) & \end{array}$

Partner's age $(M e a n=26.8, S D=4.9)$

$\begin{array}{lll}18-25 & 1.00 & \\ 26-35 & 1.10(0.710 \text { to } & 0.662 \\ & 1.715) & \\ 36-60 & \begin{array}{l}0.95(0.415 \text { to } \\ 2.172)\end{array} & 0.902\end{array}$

Partner's education

$\begin{array}{lll}\text { None/Primary } & 1.00 & \\ \text { Secondary/Tertiary } & \begin{array}{l}1.26(0.816 \text { to } \\ 1.931)\end{array} & 0.301\end{array}$

Partner's occupation

\begin{tabular}{|c|c|c|c|c|}
\hline Self employed & 1.00 & & 1.00 & \\
\hline Employed & $\begin{array}{l}1.23(0.524 \text { to } \\
2.897)\end{array}$ & 0.633 & $\begin{array}{l}1.34(0.367 \text { to } \\
4.925)\end{array}$ & 0.656 \\
\hline Unemployed & $\begin{array}{l}1.62(0.793 \text { to } \\
3.294)\end{array}$ & 0.187 & $\begin{array}{l}1.97(0.687 \text { to } \\
5.639)\end{array}$ & 0.207 \\
\hline Peasant farmer & $\begin{array}{l}1.78(0.851 \text { to } \\
3.742)\end{array}$ & 0.126 & $\begin{array}{l}1.79(0.575 \text { to } \\
5.590)\end{array}$ & 0.314 \\
\hline Student & $\begin{array}{l}1.50(0.532 \text { to } \\
4.236)\end{array}$ & 0.443 & $\begin{array}{l}7.88(0.905 \text { to } \\
8.634)\end{array}$ & 0.061 \\
\hline
\end{tabular}

Type of counselling

$\begin{array}{lll}\text { Peer counselling } & 1.00 & \\ \text { Routine counselling } & \begin{array}{l}0.90(0.630 \text { to } \\ 1.296)\end{array} & 0.582\end{array}$

Type of contraceptive method

\begin{tabular}{|c|c|c|c|c|c|}
\hline & Condoms & $\begin{array}{l}0.36(0.175 \text { to } \\
0.756)\end{array}$ & 0.007 & $\begin{array}{l}0.17(0.047 \text { to } \\
0.608)\end{array}$ & 0.007 \\
\hline \multirow[t]{2}{*}{ (pill) } & Oral contraceptives & $\begin{array}{l}0.58(0.330 \text { to } \\
1.029)\end{array}$ & 0.063 & $\begin{array}{l}0.59(0.240 \text { to } \\
1.462)\end{array}$ & 0.256 \\
\hline & Injectable & 1.00 & & 1.00 & \\
\hline
\end{tabular}


contraceptives

Reversible

Long Acting

2.59 (1.774 to

3.784)

$<0.001$

3.37 (1.914 to

$<0.001$

Time of follow up

$\begin{array}{lllll}1 \text { month } & 1.00 & & 1.00 & \\ 3 \text { months } & \begin{array}{l}0.16(0.100 \text { to } \\ 0.243)\end{array} & <0.001 & \begin{array}{l}0.12(0.067 \text { to } \\ 0.203)\end{array} & <0.001 \\ \text { 6 months } & 0.06 & <0.001 & \begin{array}{l}0.03(0.019 \text { to } \\ 0.063)\end{array} & <0.001\end{array}$

\section{Additional analyses}

Per protocol analysis: In this analysis, participants who were lost to follow up are dropped and excluded from the analysis. Results show that the variables type of contraceptive (aOR: 4.97, 95\% Cl: 1.827-13.537, $p=0.002$ for use of LARC vs SARC) and time of follow (aOR: $0.02,95 \% \mathrm{Cl}: 0.003-0.149, p<0.001$ at 6 months) were significantly associated with adherence to modern contraceptives. These conclusions are similar to those obtained from the intention to treat analysis.

Sensitivity analysis: In this analysis, participants who were lost to follow up were treated as adherent. We assumed that they continued using their contraceptives even though they were lost to follow up. Results from this analysis are similar to those obtained from the ITT and PP analyses. The only variables that were significantly associated with adherence to modern contraceptives were type of contraceptive (aOR: $3.81,95 \% \mathrm{Cl}: 1.437-10.124, p=0.007$ for use of LARC vs SARC) and the time of follow up (aOR: $0.04,95 \%$ Cl: $0.006-0.315, p=0.002$ for 6 months of follow up).

Additional analysis was also conducted to confirm if the participants who were lost to follow up are dissimilar from those who stayed in the study. Using the chi-square test, we found that the participants who completed the six months follow up are not any diferent from those who were lost to follow up as shown in table 4.

\section{Table 4}

Baseline characteristics of participants who were lost to follow up compared to those who completed the study 


\section{Variable}

Age in years

15-17

18-19

Education

training

training

Marital status

None

Primary

Secondary

Vocational

Divorced/separated

Single

Cohabiting

Married

Ever been pregnant

Yes

No

Type of counselling

counselling

Peer counselling

Routine

Type of contraceptive

Condom

Oral contraceptive

Injectable

LARC

Partner's age*
Completed follow up $(n=159)$
Lost to follow up

$(n=113)$
Pvalue

0.778

$16(14.2 \%)$

97 (85.8\%)

0.261

9 ( $7.9 \%)$

80 (70.8\%)

$22(19.5 \%)$

$2(1.8 \%)$
$28(17.6 \%)$

$3(1.9 \%)$
36 (31.9\%)

52 (46.1\%)

17 (15.0\%)

$8(7.0 \%)$
0.535

75 (66.4\%)

38 (33.6\%)

0.438

59 (52.2\%)

54 (47.8\%)

71 (44.7\%)

0.063

$12(10.6 \%)$

21 (18.6\%)

47 (41.6\%)

$33(29.2 \%)$

54 (34.0\%)

0.746

18 to 25

56 (35.2\%)

40 (35.4\%) 


\section{Discussion}

In this study that was carried out to determine the rates and predictors of adherence to modern contraceptives among female refugee adolescents in northern Uganda, participants were followed up for a period of six months. We found that adherence rates reduced with time, and that less than half of the participants adhered to the initially chosen method by the end of the study. The factors found to be associated with adherence were type of contraceptive and duration of use. Participants who were using LARCs were three times more likely to adhere to their contraceptives than those who used short acting contraceptives SARCs. The low adherence rate is in line with findings from a study among non-refugee adolescents in Ghana (28) and among non-refugee adolescents and young women aged 15 to 24 in a study carried out in northern California (29). This low adherence to modern contraceptives among refugee adolescents was mainly attributed to side effects and partner prohibition. Side effects have been reported as a cause of poor adherence in other studies among non-refugee adolescents $(20,29,30)$. Our findings are consistent with results from studies carried out among non-refugee adolescents which also found that participants who were using LARCs were more likely to adhere $(20,29)$. This can be attributed to the fact that LARCs provide a long term effective contraception without relying on user behaviour/action making it easier to adhere or comply to them (31). Furthermore, they have been preferred for their convenience of use, low failure rates, cost effectiveness (32) and high user satisfaction (33) all of which contribute to the higher adherence rates among users.

Duration of use was also significantly associated with adherence to contraceptives amongst refugee adolescents. Participants were $88 \%$ less likely to adhere to the received contraceptive at three months follow up, and over $90 \%$ less likely to adhere at six months compared with use at one month. This could be explained by the fact that participants who had adhered up to three months and continued use to six months were mostly the LARC users.

Some of the strengths of this study are: it is one of the first studies conducted to determine contraceptive adherence among refugee adolescents. It contributes to providing important information that could guide contraceptive use among refugee adolescents. The study also used a prospective cohort design which accords it more strength to understand the reasons for discontinuation at the different time points. The several time points of follow up at shorter intervals enabled us to determine the reasons for discontinuation with less recall trouble.

This study was not without limitations. First, adherence or continuation was self-reported which leaves it subject to response bias. Secondly, a sample size smaller than the calculated minimal size was used due to limited numbers of new acceptors of contraceptives in the original RCT. This left the study with a lower power to estimate associations. Lastly, over $40 \%$ of our participants were lost to follow up due to the nature of the refugee settlement where people are always moving in search for a better life, employment, 
education, and safety. This could have led to an underestimation of adherence rates and associated factors. However, we carried out a sensitivity analysis to better understand the impact of those lost to follow up, and this gave us similar conclusions to those drawn from the primary analysis.

In conclusion, adherence to reversible modern contraceptives among female refugee adolescents was very low, leaving the girls at a high risk of pregnancy and associated complications. Side effects and partner prohibition were the most reported reasons for non-adherence, so we recommend that interventions to increase knowledge on how to deal with side effects and increase partner involvement are studied and implemented. Participants who used LARCs were more likely to adhere than those who used SARCs, therefore LARCs should be recommended among adolescents especially in refugee settings, because of their ease of use and convenience coupled with greater effectiveness.

\section{Abbreviations}

RCT - Randomised controlled trial

LARC- Long acting reversible contraceptives

SARC - Short acting reversible contraceptives

IUD - Intra-uterine device

GEE - Generalised Estimating Equations

ITT - Intention to treat analysis

PP - Per protocol analysis

\section{Declarations}

\section{Ethical approval and consent to participate:}

Ethical clearance was obtained from the School of Medicine Higher Degrees Research Ethics Committee (REC REF 2018-059), and from Uganda National Council of Science and Technology (SS 4876). We ensured that all participants gave their written informed consent before enrolling them into the study, and guaranteed their confidentiality with the use of number codes instead of participant names. For participants below 18 years, we did not seek for parental consent because it is stated in the National Policy Guidelines and Service Standards for Sexual and Reproductive Health and Rights, that all individuals seeking family planning services are eligible to receive the services regardless of their age, without need for verbal or written consent from parent, guardian or spouse, as long as they have received prior education or counselling about the contraceptives (27). All interviews were held in private places where discussions could not be over heard. 


\section{Consent for publication:}

Not Applicable

\section{Availability of data and materials:}

The datasets used and/or analysed during the current study are available from the corresponding author on reasonable request.

\section{Competing interests:}

The authors declare that they have no competing interests.

\section{Funding:}

This study was funded in part by the Swedish International Development Cooperation Agency (Sida) and Makerere University under Sida contribution No: 51180060. The funder had no role in the study design, data collection and analysis, decision to publish, or preparation of the manuscript.

\section{Authors' contributions:}

RB conceptualised and designed the study, planned and carried out the analysis, interpreted results and wrote the manuscript. She is the gurantor and responsible investigator of the study. KGD, JBK, AC, EL and RCN planned and supervised the study, accessed and verified the data, contributed in analysis, interpreted results, and contributed in the writing and reviewing of the manuscript. EA contributed in data analysis, and the writing of the manuscript. All authors read and approved the final manuscript.

\section{Acknowledgements:}

We would like to acknowledge the female refugee adolescents who agreed to participate in our study, our research assistants Anthony Okello, Stella Acayo, Suzan Achayo and Richard Kidega, and the data entrant Viola Nakiwolo. Special thanks go to Errol Ssozi and Phiona Agemo for proof reading the manuscript and writing assistance.

\section{References}

1. UNICEF. Early childbearing 2019 [Available from: https://data.unicef.org/topic/childhealth/adolescent-health/. 
2. WHO. Adolescent pregnancy 2020 [Available from: https://www.who.int/en/news-room/factsheets/detail/adolescent-pregnancy.

3. UNFPA. Adolescent pregnancy. 2017.

4. Population Division D. World Population Prospects 2017, Births by five-year age group of mother, region, subregion and country, 1950-2100. 2017.

5. Sully EA, Atuyambe L, Bukenya J, Whitehead HS, Blades N, Bankole A. Estimating abortion incidence among adolescents and differences in postabortion care by age: a cross-sectional study of postabortion care patients in Uganda. Contraception. 2018;98(6):510-6.

6. Bakesiima R, Cleeve A, Larsson E, Tumwine JK, Ndeezi G, Danielsson KG, et al. Modern contraceptive use among female refugee adolescents in northern Uganda: prevalence and associated factors. Reproductive Health. 2020;17(1):67.

7. UNHCR. Baseline Study: Documenting Knowledge, Attitudes and Practices of Refugees and the Status of Family Planning Services in UNHCR's Operations in Nakivale Refugee Settlement, Uganda. 2011.

8. UNHCR. Annual Public Health Global Review 2019 [Available from: https://www.unhcr.org/606f10d04.pdf.

9. WHO. Global health estimates 2015: deaths by cause, age, sex, by country and by region, 20002015. Geneva. 2016.

10. WHO. Adolescent Pregnancy 2020 [Available from: https://www.who.int/news-room/factsheets/detail/adolescent-pregnancy.

11. Grønvik T, Fossgard Sandøy I. Complications associated with adolescent childbearing in SubSaharan Africa: A systematic literature review and meta-analysis. PLoS One. 2018;13(9):e0204327-e.

12. Kabagenyi A, Habaasa G, Rutaremwa G. Low Contraceptive Use among Young Females in Uganda: Does Birth History and Age at Birth have an Influence? Analysis of 2011 Demographic and Health Survey. Journal of contraceptive studies. 2016;1(1):4.

13. Tanabe M, Myers A, Bhandari P, Cornier N, Doraiswamy S, Krause S. Family planning in refugee settings: findings and actions from a multi-country study. Conflict and Health. 2017;11(1):9.

14. Darroch J, Woog V, Bankole A, Ashford L. Adding it up: Costs and benefits of meeting the contraceptive needs of adolescents. New York: Guttmacher Institute. 2016.

15. Blanc A, Tsui A, Croft T, Trevitt J. Patterns and trends in adolescents' contraceptive use and discontinuation in developing countries and comparisons with adult women. 35. 2009;2:63-71.

16. Blanc A, Curtis S, Croft T. Monitoring contraceptive continuation: links to fertility outcomes and quality of care, Studies in Family Planning. 2002;33(2):127-40.

17. Clare C, Fraser, C. Contraception Adherence among East Harlem Adolescents. Gynecol Obstet. 2013;3(177).

18. Richard M, Joyce, Nankumbi Okonya., Sara, Groves., Michelene, Chenault.,. Predictors of Contraceptive Adherence among Women Seeking Family Planning Services at Reproductive Health 
Uganda, Mityana Branch. International Journal of Population Research. 2015;2015.

19. Usinger KM, Gola SB, Weis M, Smaldone A. Intrauterine Contraception Continuation in Adolescents and Young Women: A Systematic Review. Journal of pediatric and adolescent gynecology. 2016;29(6):659-67.

20. Diserens C, Quach A, Mathevet P, Ballabeni P, Jacot-Guillarmod M. Adolescents' contraception continuation in Switzerland: a prospective observational study. Swiss medical weekly. 2017;147:w14504.

21. Bakesiima R, Beyeza-Kashesya, J., Tumwine, JK., Chalo, RN., Gemzell-Danielsson, K., Cleeve, A., et al Effect of peer counselling on acceptance of modern contraceptives among female refugee adolescents in northern Uganda: A randomised controlled trial. PLoS One. 2021;16(9).

22. UNHCR. Uganda - Refugee Statistics December 2020 - Palabek. 2021.

23. Hulley S. Designing Clinical Research. 4 edn2013.

24. Sznajder KK, Tomaszewski KS, Burke AE, Trent M. Incidence of Discontinuation of Long-Acting Reversible Contraception among Adolescent and Young Adult Women Served by an Urban Primary Care Clinic. Journal of Pediatric and Adolescent Gynecology. 2017;30(1):53-7.

25. Jay MS, R.H. DuRant, and I.F. Litt. Female adolescents' compliance with contraceptive regimens. Pediatr Clin North Am. 1989;36:731-46.

26. Durant RH, Jay MS, Linder CW, Shoffitt T, Litt I. Influence of psychosocial factors on adolescent compliance with oral contraceptives. Journal of Adolescent Health Care. 1984;5(1):1-6.

27. MoH. The National Policy Guidelines and Service Standards for Sexual and Reproductive Health and Rights, Uganda 2006:Pg 19-20.

28. Boamah E, Asante, KP., Mahama, E., Manu, G., Ayipah, E., Adeniji, E., Owusu-Agyei, S., https://doi.org/10.2147/OAJC.S56485. Use of contraceptives among adolescents in Kintampo, Ghana: a cross-sectional study. Open Access J Contracept. 2014;5:7-15.

29. Raine TRF-R, Anne; Upadhyay, Ushma D; Boyer, Cherrie B; Brown, Beth A; Sokoloff, Abby; Harper, Cynthia C. . One-Year Contraceptive Continuation and Pregnancy in Adolescent Girls and Women Initiating Hormonal Contraceptives. Obstetrics \& Gynecology. 2011;117:363-71.

30. Lara-Torre E, Schroeder B. Adolescent compliance and side effects with Quick Start initiation of oral contraceptive pills. Contraception. 2002;66(2):81-5.

31. Jensen JTC, Mitchell D. Speroff \& Darney's Clinical Guide to Contraception. 6th Edition ed2019.

32. Stoddard A, McNicholas C, Peipert JF. Efficacy and safety of long-acting reversible contraception. Drugs. 2011;71(8):969-80.

33. Secura GM, Allsworth JE, Madden T, Mullersman JL, Peipert JF. The Contraceptive CHOICE Project: reducing barriers to long-acting reversible contraception. Am J Obstet Gynecol. 2010;203(2):115.e1-.e1157.

\section{Figures}




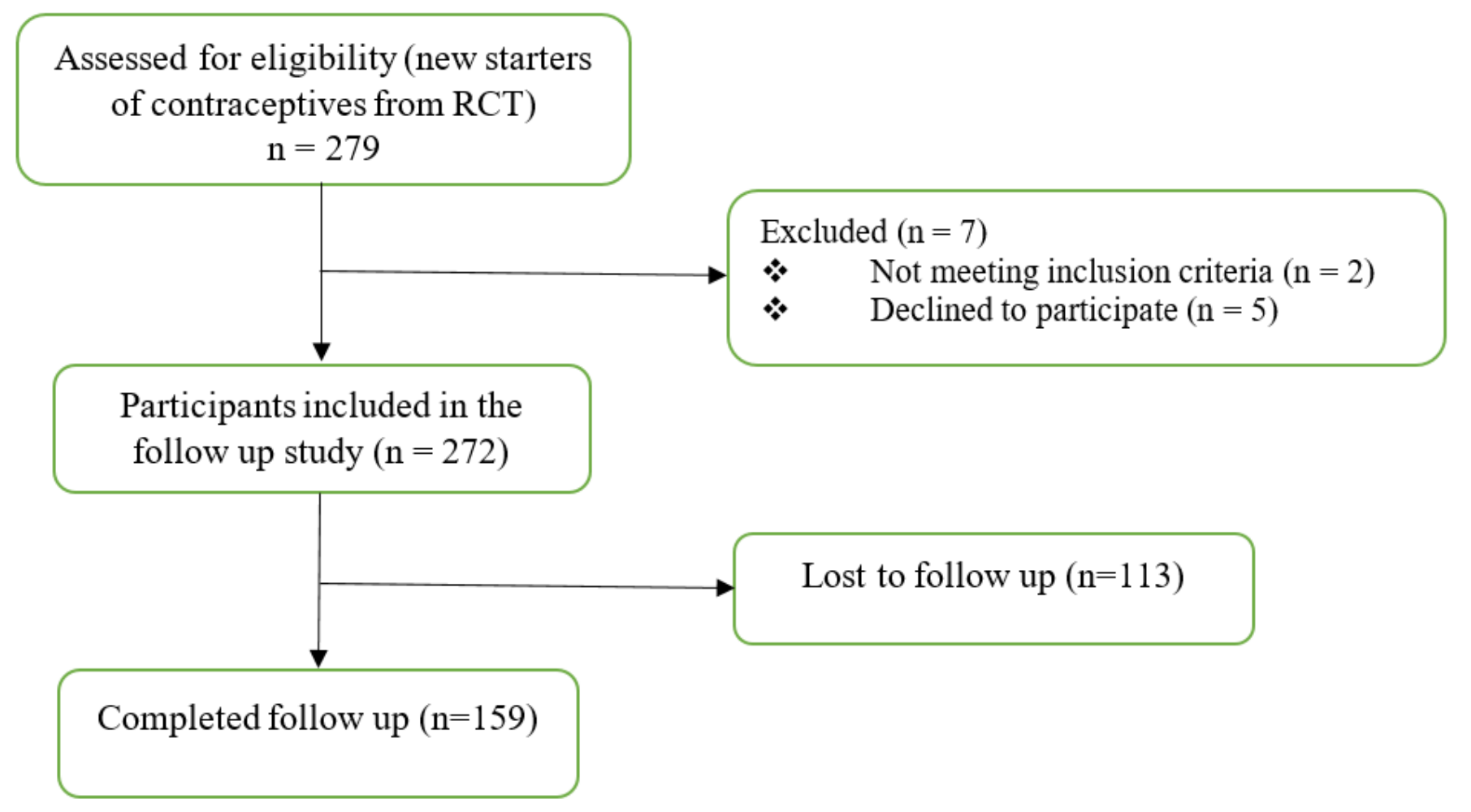

Figure 1

Participant flow chart 